\title{
Outpatient Endocrine Diagnosis and Treatment of Thyroid Diseases and Disorders in a Portuguese Public University Hospital
}

\author{
Joao Martin Martins ${ }^{\mathrm{a}, \mathrm{f}, \mathrm{g}}$, Dinis Reis ${ }^{\mathrm{a}, \mathrm{f}}$, Lucas Batista ${ }^{\mathrm{b}, \mathrm{f}}$, Filipa Parames , $^{\mathrm{c}}$, \\ Margarida Mendes de Almeida ${ }^{\mathrm{d}, \mathrm{f}}$, Guilhermina Cantinho e, $\mathrm{f}^{\mathrm{f}}$
}

\begin{abstract}
Background: Thyroid diseases and disorders account for most of the activity of outpatient endocrine departments, but objective data regarding the care of such patients is difficult to find. Knowledge of that data would be fundamental for the planning of those departments and to develop translational research.
\end{abstract}

Methods: A specific database was defined using the Statistical Package for the Social Sciences Program (SPSS IBM, 24th version, 2017) to include the records of all patients assisted by one of us, between January 2005 and December 2016, at the outpatient endocrine department of a public university hospital. Clinical and analytical data regarding the first and last visits was included. Statistical analysis used the same software program.

Results: A total of 1,222 patients were included. Diagnostic groups were: 1) Simple nodular goiter (SNG) $(46 \%)$; 2) Hashimoto's thyroiditis (HT) $(29 \%)$; 3) Graves' disease (GD) $(10 \%)$; 4) Toxic nodular goiter (TNG) (7\%); and 5) Thyroid neoplasia (TN) (5\%). After a mean follow-up of 5 years most patients with GD (70\%), TNG (77\%), HT (67\%) and TN (92\%) but no patients with SNG (32\%) had either received definitive treatment or were being treated. However the euthyroid state was far from universal and not significantly different across groups (62-86\%).

Conclusions: Continued specialist care of patients with thyroid diseases and disorders is far from perfect. It corrects thyroid dysfunction in most but not all patients and most patients remain on thyroid medications, despite definitive treatment in many. Long-term follow-up

Manuscript submitted February 3, 2019, accepted March 2, 2019

aEndocrine Department, Santa Maria Hospital, Lisbon, Portugal

bSurgery Department, Santa Maria Hospital, Lisbon, Portugal

${ }^{\circ}$ Clinical Pathology Department, Santa Maria Hospital, Lisbon, Portugal

dPathology Department, Santa Maria Hospital, Lisbon, Portugal

eNuclear Medicine Department, Santa Maria Hospital, Lisbon, Portugal

${ }^{f}$ Lisbon Medical School, Lisbon, Portugal

'Corresponding author: Joao Martin Martins, Servico de Endocrinologia, Piso

6, Hospital de Santa Maria, Av. Professor Egas Moniz, Lisbon 1649-028, Por-

tugal. Email: jmartinmartins@sapo.pt

doi: https://doi.org/10.14740/jem550 of these patients is probably the responsibility of the endocrine team. Otherwise major complications may come to the attention of the specialists only when late recognition occurs by general physicians or internists.

Keywords: Thyroid diseases; Hospital outpatient care; Outcomes

\section{Introduction}

Thyroid diseases and disorders are the major group of medical conditions assisted at the outpatient endocrine department of many central public hospitals $[1,2]$. In fact they, together with diabetes mellitus, dominate by far the activity of such departments even if some endocrinologists choose not to assist diabetic patients $[1,2]$.

Endocrinologists therefore gather a lot of experience and expertise regarding thyroid diseases and disorders and must be able to objectively report long-term follow-up and outcomes; these data may help identify pitfalls in diagnosis, complications usual and unusual, define the natural course of these diseases and disorders as modified by modern medical intervention, compare the activity of different centers and settings, compare treatment options when available, and ultimately help define the always changing best approach regarding the diagnosis and management of those conditions. In the end they may be able to better understand these disorders and diseases and may give food for thought for basic research or what is now termed translational research, from the bench to the patient bed or chair at the outpatient department.

Objective evaluation of the assistance regarding thyroid diseases and disorders is also of the outmost importance for the planning of such departments, namely to identify specific needs, and define its place in the hospital and in the community it serves, including the dialog with the general physicians referring the patients. This evaluation may be compared with that regarding a completely different endocrine condition, such as diabetes mellitus for which a recent report has been published [3].

This report presents objective data regarding specialist outpatient care of thyroid diseases and disorders in a public tertiary hospital. More than the specific details, the general 
data, long-term follow-up and outcomes are described.

\section{Patients and Methods}

We included in a specific database defined using the Statistical Package for the Social Sciences Program (SPSS IBM, 24th version, 2017) the records of all patients assisted by one of us, between January 2005 and December 2016, at the outpatient endocrine department of a public central university hospital. Data regarding the first and last visits was included: 1) First visit-name initials, hospital number, sex, age, year of first visit, new patient or not for the doctor and new case or not (meaning now diagnosed), diagnosis modified by later evaluation if necessary, years since diagnosis, treatment at the first visit and endocrine evaluation at the first visit including as appropriate triiodothyronine (T3), thyroxine (T4), thyroid stimulating hormone (TSH), free thyroxine (fT4), thyroid peroxidase antibodies (TPOAbs), thyroglobulin antibodies (TgAbs), TSH receptor antibodies (TRAbs), thyroglobulin (Tg), calcitonin, sonographic evaluation, fine needle aspirative biopsy (FNAB) and isotopic thyroid scan; and 2) Last visit-year of the last visit, number of visits, treatment and the same endocrine analytical evaluation as before.

Patients were assisted at the outpatient endocrine department, either in the morning $(8-14 \mathrm{~h})$ or in the noon period $(14-20 \mathrm{~h})$ in general endocrinology visits. Blood samples were collected in the morning $(8-10 \mathrm{~h})$ after the overnight fast in the Clinical Pathology Department. Standard immune chemiluminescent immunoassay (CLIA) was used and performed in the Clinical Pathology Department. Reference values for the selected variables were as follows: T3 $60-180$ $\mathrm{ng} / \mathrm{dL}$, T4 $4.5-11 \mu \mathrm{g} / \mathrm{dL}$, fT4 $0.9-1.8 \mathrm{ng} / \mathrm{dL}$, TSH 0.35 - $5.50 \mu \mathrm{U} / \mathrm{mL}$, TPOAb $<40 \mathrm{U} / \mathrm{mL}, \mathrm{TgAb}<40 \mathrm{U} / \mathrm{mL}, \mathrm{TRAb}$ $<1 \mathrm{U} / \mathrm{L}, \mathrm{Tg}<55 \mathrm{ng} / \mathrm{mL}$, and calcitonin $<5 \mathrm{pg} / \mathrm{mL}$. Thyroid sonographic examination was performed at the Imagiology Department using a commercially available real-time scanner equipped with a linear transducer operating at $8.5-13$ MHz. Thyroid dimensions, homogeneity or heterogeneity, the presence and number and characteristic of any nodules were recorded including shape, dimensions, contours, halo sign and echogenicity. FNAB was performed at the Pathology Department using a 22- to 25 -gauge and 4.5 -cm-long needle attached to a syringe and the samples were air-dried and colored with the Romanowsky and Papanicolau stains; results were reported according to the Bethesda system [4]. Thyroid ${ }^{99} \mathrm{Tc}(5 \mathrm{mCi})$ scans were obtained at the Nuclear Medicine Department.

Data was retrieved anonymously from the clinical records of patients assisted at a public central university hospital according to the Standards of Clinical Care and the study fully complies with the Declaration of Helsinki regarding ethical guidelines for research in human subjects. Critical evaluation of care is the duty of doctors assisting patients in a public central university hospital as defined by the Institutional Review Board.

Major diagnostic groups were defined as follows: 1) Simple nodular goiter (SNG)-increased thyroid dimensions $(>5$ $\mathrm{cm}$ larger diameter) and/or thyroid nodules larger than $5 \mathrm{~mm}$, with negative thyroid antibodies and normal thyroid function [5]; 2) Hashimoto's thyroiditis (HT) defined as positive thyroid antibodies, TPOAb and/or TgAb $>40 \mathrm{U} / \mathrm{L}$, with or without thyroid nodules defined as before and with normal thyroid function or hypothyroidism [6]; 3) Graves' disease (GD) defined as hyperthyroidism with positive TRAb $>2 \mathrm{U} / \mathrm{L}$ [7]; 4) Toxic nodular goiter (TNG) defined as hyperthyroidism with a ${ }^{99} \mathrm{Tc}$ thyroid scan with evidence of uptake in one or more thyroid nodules with suppression of the remaining tissue [8]; 5) Thyroid neoplasia (TN) including follicular tumor, follicular adenoma and papillary, follicular, undifferentiated and medullary thyroid carcinoma as defined by pathologic examination [9].

Thyroid dysfunction was defined by a TSH outside the reference range; subclinical hyperthyroidism (SCHyper) was considered when TSH was $<0.35 \mu \mathrm{U} / \mathrm{mL}$ and T3, T4, and fT4 were normal and subclinical hypothyroidism (SCHypo) was considered when TSH was $>5.5 \mu \mathrm{U} / \mathrm{mL}$ and T3, T4 and fT4 were normal [5-9].

Regarding treatment, for the purpose of this report both thyroid surgery and radioactive iodide were considered definitive treatments, and medical treatment either levothyroxine and/or anti-thyroid drugs like propylthiouracil and thiamazole was considered non-definitive treatment [5-9].

Data was analyzed using the same program (SPSS IBM, 24th version, 2016). Results are presented as the mean \pm standard deviation or as percentage as appropriate. The normal distribution of continuous variables was verified with the Kolmogorov-Smirnov test and non-normal distributed variables were log transformed prior to analysis or non-parametric tests were used. For the sake of simplicity however when non-significant differences were found, results regarding nontransformed variables were presented. Differences between groups used the Chi-square test $\left(\chi^{2}\right)$, Wilcoxon or Anova as appropriate with the least square difference for post hoc analysis. Differences between the first and last visits were evaluated using paired analysis Student's $t$-test, paired Wilcoxon or Anova, and the relation between continuous variables with factorial regression analysis. The limit of statistical significance was set at 0.05 [10-12].

\section{Results}

Between January 2005 and December 2016 (12 years) we assisted 1,222 patients with thyroid diseases and disorders, around 200 new patients in the first year and then around 100 new patients in every consecutive year. Considering their first and last appointments at the department, 701 patients $(69 \%)$ were new cases, with a total number of 7,100 visits, $6 \pm 4$ visits per patient, and 798 patients $(66 \%)$ were still assisted at the department while the remainder were presumptively lost for the follow-up or referred to other institutions if TN was present. Comparatively, for the same time period a total number of 18,000 visits were the responsibility of a single physician, and 647 diabetic patients were assisted, with a mean of $7 \pm 7$ visits and a total number of 4,814 visits (Fig. 1a). 

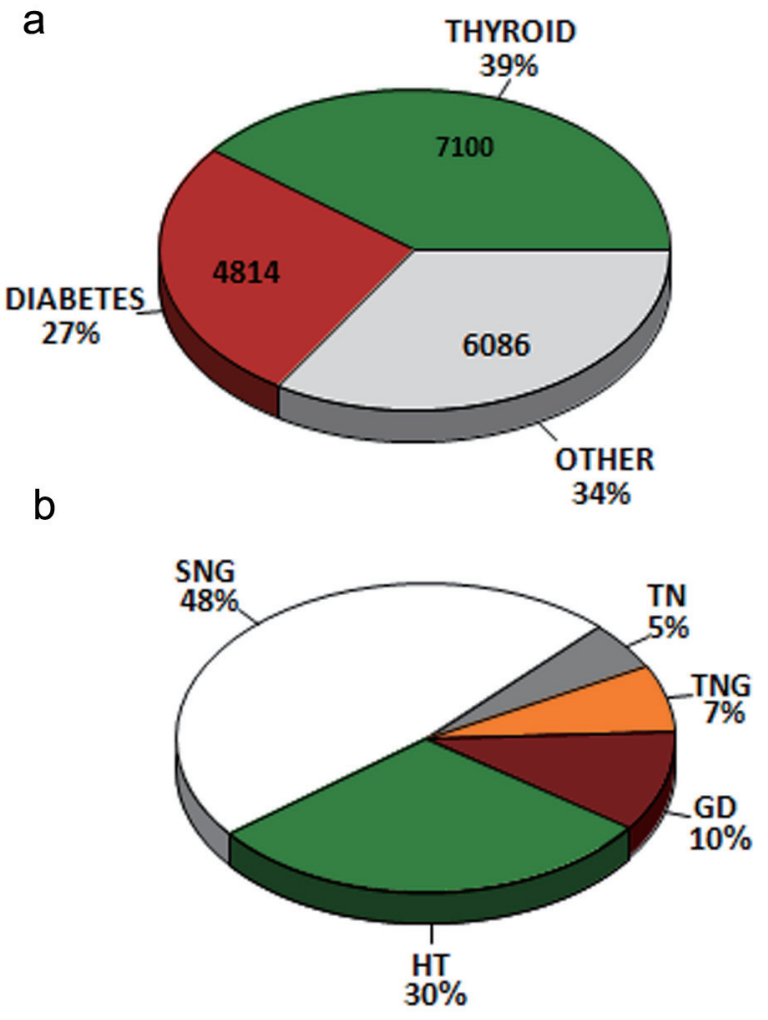

Figure 1. (a) Distribution of patient visits at the outpatient endocrine department between 2005 and 2016. Absolute numbers are indicated within the pie and percent numbers outside. (b) Thyroid diagnostics for patient visits at the outpatient endocrine department between 2005 and 2016. GD: Graves' disease; HT; Hashimoto's thyroiditis; SNG: simple nodular goiter; TN: thyroid neoplasia; TNG: toxic nodular goiter.

Major diagnostic groups as previously defined included: 1) SNG 563 patients (46\%); 2) HT 349 patients (29\%); 3) GD 123 patients (10\%); 4) TNG 82 patients (7\%); and 5) TN 61 patients $(5 \%)$. Together these include $97 \%$ of the patients (Fig. 1b). Common general characteristics are first presented (Table 1).

Sex was significantly different (statistical trend) across diagnostic groups $\left(\chi^{2}=9.303, \mathrm{df}=4, \mathrm{P}<0.06\right)$, with significantly more male patients in GD $(19 \%)$ than in all other groups $(10-14 \%)$. Age was also significantly different $(\mathrm{F}(4,1132)=$ 22.297, $\mathrm{P}<0.001$ ), with patients with GD being the younger $(44 \pm 16)$ followed by patients with HT $(51 \pm 17)$ and patients with TN $(53 \pm 14)$, and then the patients with SNG $(56 \pm 15)$ and TNG $(61 \pm 14)$.

Considering data regarding the first appointment, there were no significant differences regarding the rate of new cases across diagnostic groups (67-85\%), nor regarding the year of the first visit (2009 - 2010); however the year of diagnosis was significantly different (statistical trend) across diagnostic groups $(\mathrm{F}(4,148)=2.030, \mathrm{P}<0.1)$, with patients with GD $(2004 \pm 9)$ and HT $(2005 \pm 8)$ being those with longer period of time since diagnosis, and those with SNG with more recent diagnosis $(2009 \pm 7)$, while patients with TNG and TN presented intermediate values (2007 \pm 4 and $2007 \pm 6$, respectively).
Thyroid dysfunction (hyper- or hypothyroidism) was significantly different across diagnostic groups $\left(\chi^{2}=374.951, \mathrm{df}=8\right.$, $\mathrm{P}<0.001)$, which was much more common in GD $(74 \%)$ and TNG $(78 \%)$ and then in HT (37\%) followed by in SNG or TN (13\% in each case). Also treatment already at the first visit was significantly different across diagnostic groups $\left(\chi^{2}=149.605\right.$, $\mathrm{df}=4, \mathrm{P}<0.001)$, being much more common in patients with GD (68\%) and then in those with HT (48\%) and TN (46\%) followed by those with TNG $(25 \%)$ or SNG $(20 \%)$.

Considering the last appointment, year of last visit (2014), the ratio of those retained (60-68\%) and the time of follow-up (4 - 6 years) were also not significantly different across diagnostic groups. However time since diagnosis was significantly different across diagnostic groups (statistical trend) $(\mathrm{F}(4,239)$ $=2.257, \mathrm{P}<0.06)$, which was longer in patients with GD $(9 \pm$ $9)$ and HT $(8 \pm 8)$ than in all other groups (TN $7 \pm 6$, SNG 6 \pm 7 and TNG $5 \pm 7$ ). The number of appointments during the follow-up period was also significantly different $(\mathrm{F}(4,240)=$ 4.211, P < 0.05) with patients with GD $(8 \pm 6)$, HT $(7 \pm 4)$ and

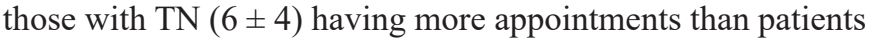
with TNG $(5 \pm 4)$ or SNG $(5 \pm 3)$. Again therapy at the last appointment was significantly different across diagnostic groups $\left(\chi^{2}=152.790, \mathrm{df}=4, \mathrm{P}<0.001\right)$, with almost all patients with TN being treated (92\%) significantly more than those with either GD (70\%), TNG (77\%), or HT (67\%), and all significantly more than those with SNG (32\%). However there were no differences regarding euthyroid status across groups at the final visit $(62-86 \%)$.

The T3/T4 ratio (no dimensional) at the first visit was significantly different across diagnostic groups $(\mathrm{F}(4,1053)=$ $27.72, \mathrm{P}<0.001$ ), which was higher in patients with GD and then in those with TNG than in those with either HT, SNG or $\mathrm{TN}$. There were no differences regarding the same ratio at the last visit. At the first visit Tg levels were significantly higher in patients with TN than in all other groups $(\mathrm{F}(4,596)=9.489$, $\mathrm{P}$ $<0.001$ ); if patients with TN were excluded from the analysis then patients with GD and TNG presented significantly higher levels than patients with either HT or SNG $(\mathrm{F}(3,558)=3.229$, $\mathrm{P}<0.03)$; there were no differences regarding values at the last visit. Again at the first visit calcitonin levels were significantly higher in patients with $\mathrm{TN}$ than in all other groups $(\mathrm{F}(4,488)$ $=3.328, \mathrm{P}<0.02)$, also with no difference regarding values at the last visit.

We now present results regarding specific conditions.

\section{GD}

Regarding the 123 patients with GD as previously defined, results are presented in Table 2 and Figure 2.

Most patients were already under treatment at the first visit (68\%)-10\% had already received radioactive iodine and $2 \%$ had received surgery and $56 \%$ were under antithyroid and/ or levothyroxine-and only half were still hyperthyroid (50\%) (37\% with clinical hyperthyroidism and 13\% with SCHyper) while some were euthyroid (26\%) and some were hypothyroid $(24 \%)(15 \%$ with clinical hypothyroidism and $9 \%$ with SCHypo).

After a mean follow-up of $5 \pm 5$ years, and regarding the 
Table 1. Common General Characteristics Across Diagnostic Groups

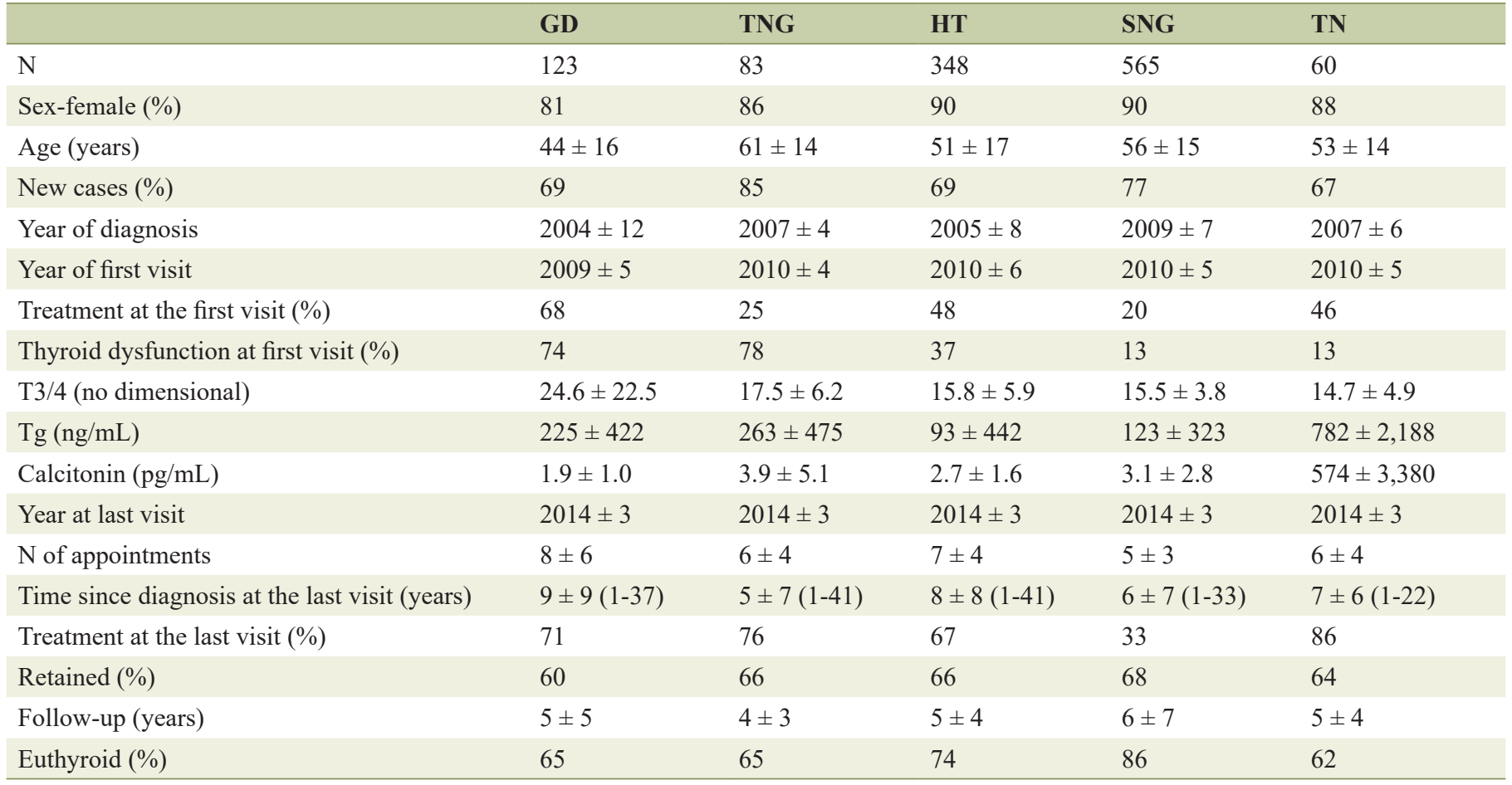

GD: Graves' disease; TNG: toxic nodular goiter; HT: Hashimoto's thyroiditis; SNG: simple nodular goiter; TN: thyroid neoplasia.

last available appointment, the majority $(65 \%)$ were euthyroid, while the remaining presented for the most part subclinical dysfunction (5\% clinical hyperthyroidism and 10\% SCHyper and 3\% with clinical hypothyroidism and 17\% with SCHypo). However few patients were free of medication (29\%); most were still using anti-thyroid medication either isolated or com- bined with levothyroxine (37\%), 20\% had been treated with radioactive iodine (14 out of 21 were now taking levothyroxine), $8 \%$ had been treated with surgery and all were taking levothyroxine, and 6\% were taking levothyroxine despite no previous definitive treatment. Time since diagnosis is now 9 \pm 9 years.

Table 2. Graves' Disease $(n=123)$

\begin{tabular}{llll}
\hline & First visit & Last visit & P \\
\hline Sex & $2009 \pm 5$ & $2014 \pm 3$ & \\
Age (years) & Female $81 \%$ & & $<0.05$ \\
T3 (ng/dL) & $44 \pm 16$ & $125 \pm 74$ & $<0.05$ \\
T4 $(\mu \mathrm{g} / \mathrm{dL})$ & $207 \pm 176$ & $8.9 \pm 2.8$ & $<0.05$ \\
FT4 $(\mathrm{ng} / \mathrm{dL})$ & $10.5 \pm 6.8$ & $1.3 \pm 0.7$ & $<0.05$ \\
TSH $(\mu \mathrm{U} / \mathrm{mL})$ & $1.8 \pm 1.8$ & $4.5 \pm 9.8$ & $<0.05$ \\
TPOAb $(\mathrm{U} / \mathrm{mL})$ & $8.6 \pm 26.6$ & $745 \pm 2,220$ & $<0.05$ \\
TgAb $(\mathrm{U} / \mathrm{mL})$ & $2,024 \pm 12,176$ & $213 \pm 565$ & $23 \pm 15$ \\
TRAb $(\mathrm{U} / \mathrm{L})$ & $204 \pm 458$ & $60 \pm 101$ & $<0.05$ \\
Tg $(\mathrm{ng} / \mathrm{mL})$ & $28 \pm 61$ & $14.1 \pm 4.8$ & \\
T3/T4 (no dimensional) & $225 \pm 422$ & & \\
Enlarged thyroid $(\%)$ & $24.6 \pm 22.5$ & & \\
Thyroid nodules $(\%)$ & $61 \%$ & & \\
\hline
\end{tabular}

T3: triiodothyronine; T4: thyroxine; TSH: thyroid stimulating hormone; fT4: free thyroxine; TPOAb: thyroid peroxidase antibody; TgAb: thyroglobulin antibody; TRAb: TSH receptor antibody; Tg: thyroglobulin. 


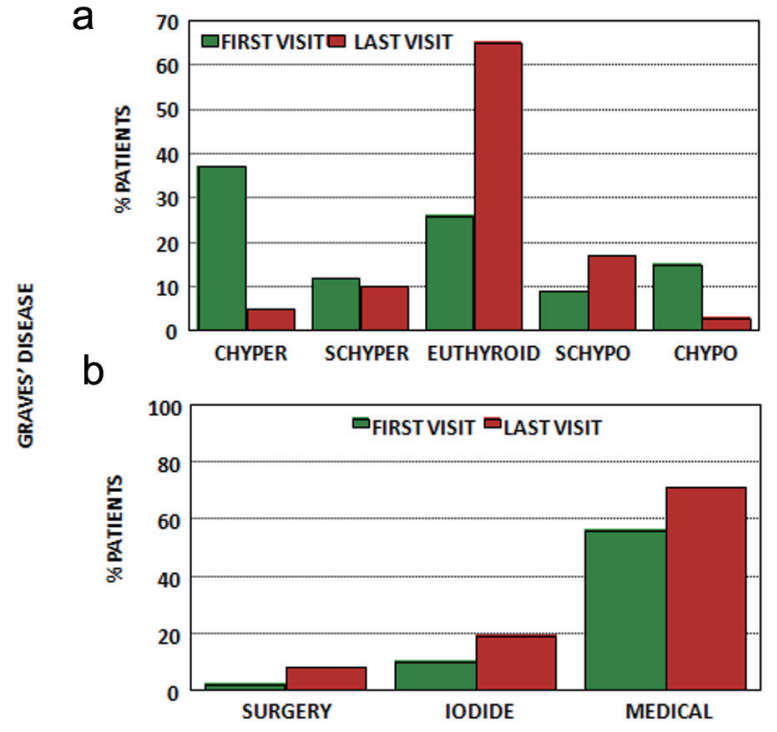

Figure 2. (a) Thyroid function at first and last visits for patients with Graves' disease. (b) Treatment at first and last visits for patients with Graves' disease. CHyper: clinical hyperthyroidism; SCHyper: subclinical hyperthyroidism; Euthyroid: euthyroidism; SCHypo: subclinical hypothyroidism; CHypo: clinical hypothyroidism; lodide: radioactive iodide; medical treatment: anti-thyroid drugs and/or levothyroxine (see text)

\section{TNG}

These results may be contrasted regarding the 83 patients with TNG as previously defined (Table 3 and Fig. 3).

The majority was without thyroid therapy at the first appointment $(75 \%)$, but $14 \%$ were already under anti-thyroid treatment and $11 \%$ had previously been treated either with radioactive iodine $(5 \%)$ or partial thyroidectomy $(6 \%)$ and were

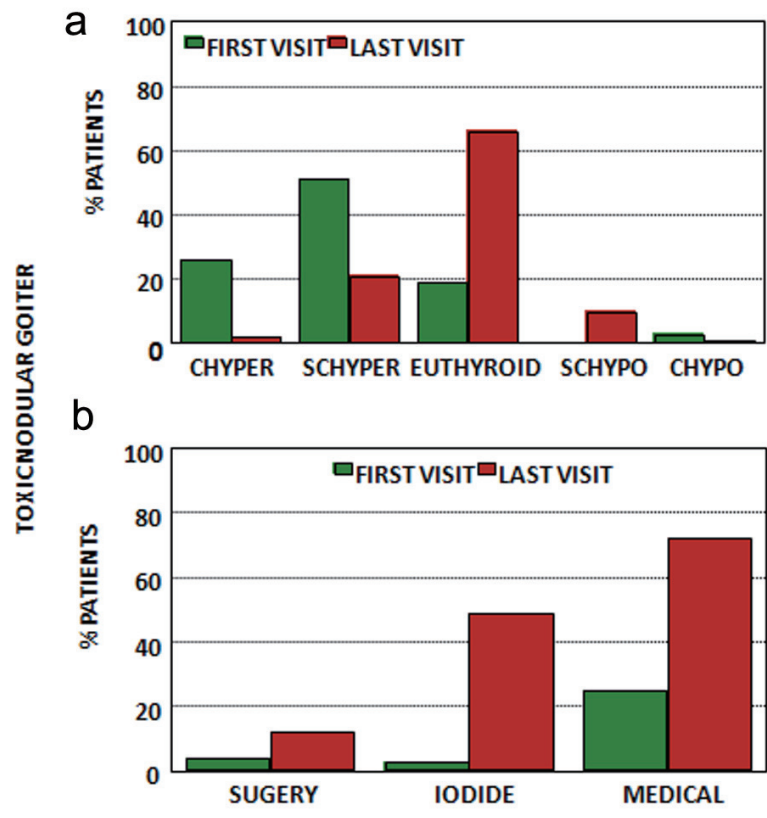

Figure 3. (a) Thyroid function at first and last visits for patients with toxic nodular goiter. (b) Treatment at first and last visits for patients with toxic nodular goiter. CHyper: clinical hyperthyroidism; SCHyper: subclinical hyperthyroidism; euthyroid: euthyroidism; SCHypo: subclinical hypothyroidism; CHypo: clinical hypothyroidism; iodide: radioactive iodide; medical treatment: anti-thyroid drugs and/or levothyroxine (see text).

using levothyroxine; $6 \%$ were using amiodarone. Under these conditions at the first appointment $78 \%$ were hyperthyroid (26\% clinical hyperthyroidism, 51\% SCHyper), 19\% were euthyroid and $3 \%$ were hypothyroid (all clinical hypothyroidism).

At the last appointment and after a mean follow-up of $4 \pm$

Table 3. Toxic Nodular Goiter $(n=82)$

\begin{tabular}{llll}
\hline & First visit & Last visit & P \\
\hline Sex & $2010 \pm 4$ & $2014 \pm 3$ & \\
Age (years) & Female $86 \%$ & & $<0.05$ \\
T3 (ng/dL) & $61 \pm 14$ & $118 \pm 34$ & $<0.05$ \\
T4 $(\mu \mathrm{g} / \mathrm{dL})$ & $172 \pm 101$ & $10.2 \pm 14.7$ & $1.2 \pm 0.4$ \\
FT4 $(\mathrm{ng} / \mathrm{dL})$ & $9.9 \pm 3.9$ & $2.0 \pm 3.4$ & $20 \pm 17$ \\
TSH $(\mu \mathrm{U} / \mathrm{mL})$ & $1.8 \pm 2.0$ & $20 \pm 21$ & $<0.05$ \\
TPOAb $(\mathrm{U} / \mathrm{mL})$ & $0.9 \pm 4.1$ & $113 \pm 185$ & $14.2 \pm 4.6$ \\
TgAb $(\mathrm{U} / \mathrm{mL})$ & $43 \pm 132$ & & $<0.05$ \\
Tg $(\mathrm{ng} / \mathrm{mL})$ & $33 \pm 91$ & \\
T3/T4 (no dimensional) & $263 \pm 475$ & & \\
Enlarged thyroid $(\%)$ & $17.5 \pm 6.2$ & & \\
Thyroid nodules $(\%)$ & $71 \%$ & $97 \%$ & \\
\hline
\end{tabular}

T3: triiodothyronine; T4: thyroxine; TSH: thyroid stimulating hormone; fT4: free thyroxine; TPOAb: thyroid peroxidase antibody; TgAb: thyroglobulin antibody; Tg: thyroglobulin. 
Table 4. Hashimoto's Thyroiditis $(n=349)$

\begin{tabular}{llll}
\hline & First visit & Last visit & P \\
\hline Sex & $2010 \pm 6$ & $2014 \pm 3$ & \\
Age (years) & Female $90 \%$ & & $<0.05$ \\
T3 (ng/dL) & $51 \pm 17$ & $109 \pm 32$ & $8.6 \pm 2.4$ \\
T4 $(\mu \mathrm{g} / \mathrm{dL})$ & $131 \pm 45$ & $1.3 \pm 0.6$ & $<.9 \pm 9.1$ \\
FT4 $(\mathrm{ng} / \mathrm{dL})$ & $8.7 \pm 2.5$ & $538 \pm 1,950$ \\
TSH $(\mu \mathrm{U} / \mathrm{mL})$ & $1.3 \pm 3.3$ & $501 \pm 2,402$ & $<0.05$ \\
TPOAb $(\mathrm{U} / \mathrm{mL})$ & $7.7 \pm 29.2$ & $50 \pm 240$ \\
TgAb $(\mathrm{U} / \mathrm{mL})$ & $973 \pm 4,237$ & $14.1 \pm 15.6$ \\
Tg $(\mathrm{ng} / \mathrm{mL})$ & $775 \pm 4,070$ & \\
T3/T4 (no dimensional) & $93 \pm 442$ & \\
Enlarged thyroid $(\%)$ & $15.8 \pm 5.9$ & \\
Decreased thyroid $(\%)$ & $34 \%$ & \\
Nodules $(\%)$ & $9 \%$ & \\
\hline
\end{tabular}

T3: triiodothyronine; T4: thyroxine; TSH: thyroid stimulating hormone; fT4: free thyroxine; TPOAb: thyroid peroxidase antibody; TgAb: thyroglobulin antibody; Tg: thyroglobulin.

3 years, $65 \%$ were euthyroid, $23 \%$ were still hyperthyroid $(2 \%$ clinical and $21 \%$ subclinical) and $11 \%$ were hypothyroid $(9 \%$ subclinical and $2 \%$ clinical). Many patients (49\%) were treated with radioactive iodine and among them $70 \%$ were with no levothyroxine and $30 \%$ were with levothyroxine, and $12 \%$ had thyroidectomy and were using levothyroxine, and globally $72 \%$ either had definitive treatment or were using anti-thyroid and/or levothyroxine, but $24 \%$ had no definitive treatment and were not using anti-thyroid drugs.

\section{HT}

Results regarding the 349 patients with HT as previously defined are presented in Table 4 and Figure 4.

Regarding the first appointment, half of the patients were already under treatment with levothyroxine (48\%), and while the majority (63\%) was euthyroid, almost one-third $(29 \%)$ were hypothyroid (19\% subclinical and 10\% clinical) and $8 \%$ were hyperthyroid due to the medicine $(2 \%$ clinical and $6 \%$ subclinical).

At the last appointment and after a mean follow-up of $4 \pm$ 6 years, the vast majority of the patients were euthyroid (74\%) with a small fraction with hyperthyroidism (9\%) (2\% clinical, and $7 \%$ subclinical) and a larger fraction with hypothyroidism $(17 \%-11 \%$ subclinical and $6 \%$ clinical) but most patients $(67 \%)$ were under treatment with levothyroxine.

\section{SNG}

Results regarding the largest group of patients, those with SNG, are presented in Table 5 and Figure 5.

Clinically and/or sonographically most (88\%) had simple multinodular goiter while only a minority $(12 \%)$ presented a single/dominant nodular goiter. In almost half FNAB was obtained.

At the first appointment many of these patients were already under treatment- $7 \%$ had undergone partial thyroid-

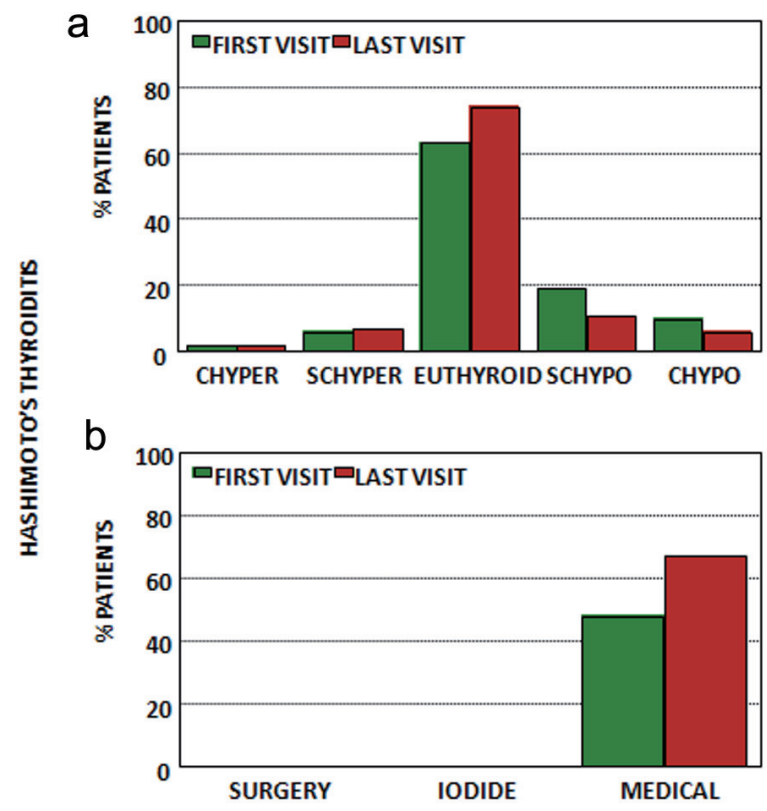

Figure 4. (a) Thyroid function at first and last visits for patients with Hashimoto's thyroiditis. (b) Treatment at first and last visits for patients with Hashimoto's thyroiditis. CHyper: clinical hyperthyroidism; $\mathrm{SCHy}-$ per: subclinical hyperthyroidism; euthyroid: euthyroidism; SCHypo: subclinical hypothyroidism; $\mathrm{CHypo}$ : clinical hypothyroidism; iodide: radioactive iodide; medical treatment: anti-thyroid drugs and/or levothyroxine (see text). 
Table 5. Simple Nodular Goiter $(n=563)$

\begin{tabular}{llll}
\hline & First visit & Last visit & P \\
\hline Sex & $2010 \pm 5$ & $2014 \pm 3$ & \\
Age (years) & Female $90 \%$ & & \\
T3 $(\mathrm{ng} / \mathrm{dL})$ & $56 \pm 15$ & $111 \pm 26$ & 0.05 \\
T4 $(\mu \mathrm{g} / \mathrm{dL})$ & $132 \pm 37$ & $8.8 \pm 6.0$ & $1.2 \pm 0.6$ \\
FT4 $(\mathrm{ng} / \mathrm{dL})$ & $8.6 \pm 1.8$ & $2.5 \pm 5.0$ \\
TSH $(\mu \mathrm{U} / \mathrm{mL})$ & $1.2 \pm 0.4$ & $86 \pm 391$ \\
Tg $(\mathrm{ng} / \mathrm{mL})$ & $2.0 \pm 3.6$ & $13.6 \pm 4.6$ \\
T3/T4 $($ no dimensional) & $124 \pm 324$ & \\
Enlarged thyroid $(\%)$ & $15.5 \pm 3.8$ & \\
Nodules $(\%)$ & $50 \%$ & \\
Cytology & $97 \%$ & \\
\hline
\end{tabular}

T3: triiodothyronine; T4: thyroxine; TSH: thyroid stimulating hormone; fT4: free thyroxine; Tg: thyroglobulin; B: benign; ND: non-diagnostic.

ectomy and were under levothyroxine treatment, $12 \%$ were under levothyroxine treatment and less than $1 \%$ were using anti-thyroid medications. Although the vast majority $(87 \%)$ was euthyroid, a small group (8\%) was hyperthyroid (less than $1 \%$ clinical and $7 \%$ subclinical) and a smaller group was hypothyroid (5\%-4\% subclinical and 1\% clinical).

At the last appointment after a mean follow-up of $4 \pm 4$ years, again the vast majority were euthyroid (86\%) with a small group being hyperthyroid (6\%) (all with SCHyper) and $8 \%$ being hypothyroid (5\% subclinical and 3\% clinical); however by now many had been subject to partial or total thyroidectomy and were using levothyroxine treatment (22\%), while $11 \%$ were under levothyroxine treatment and only $67 \%$ were without treatment.

\section{TN}

Finally we consider patients with TN (Table 6, Fig. 6).

We assisted 61 patients with TN subdivided as follows: six with follicular tumor, 11 with follicular adenoma, 37 with papillary carcinoma, three with follicular carcinoma, two with undifferentiated carcinoma and two with medullary carcinoma.

At the first appointment, only $42 \%$ were not under treatment; in fact $17 \%$ had already been subject to surgery, $5 \%$ to surgery and radioactive iodine and 36\% were under levothyroxine. There were $13 \%$ patients with hyperthyroidism $(3 \%$ clinical and $10 \%$ subclinical) and no patient with hypothyroidism.

In the last appointment and after a mean follow-up of $5 \pm$ 5 years, $77 \%$ had been submitted to surgery and were under levothyroxine treatment, $9 \%$ had been submitted to surgery and radioactive iodine and were under levothyroxine treatment and $14 \%$ are waiting for surgery. There were $28 \%$ patients with hyperthyroidism (26\% subclinical and $2 \%$ clinical) and $10 \%$ patients with hypothyroidism (5\% subclinical and $5 \%$ clinical).

\section{Discussion}

Thyroid diseases are very common in the general adult population [13-15]. Even when considering only thyroid dysfunction, hyperthyroidism almost always GD or TNG occur in 3-4\% of the general population, and hypothyroidism almost always HT occur in 3-5\%. Thyroid nodules greater than $10 \mathrm{~mm}$, generally

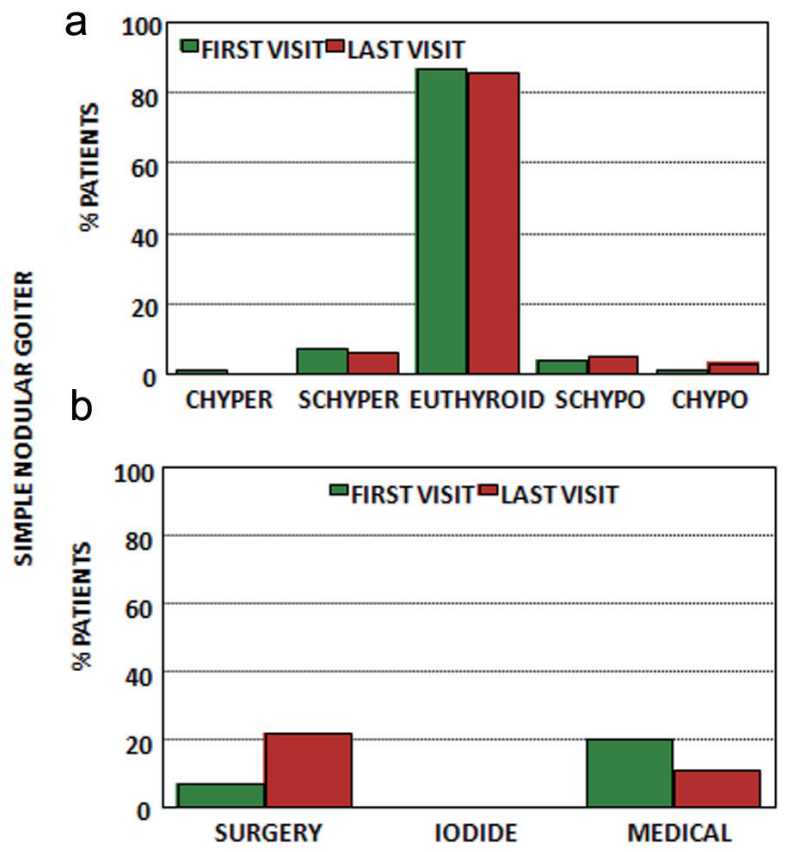

Figure 5. (a) Thyroid function at first and last visits for patients with simple nodular goiter. (b) Treatment at first and last visits for patients with simple nodular goiter. CHyper: clinical hyperthyroidism; SCHyper: subclinical hyperthyroidism; euthyroid: euthyroidism; SCHypo: subclinical hypothyroidism; CHypo: clinical hypothyroidism; iodide: radioactive iodide; medical treatment: anti-thyroid drugs and/or levothyroxine (see text). 
Table 6. Thyroid Neoplasia $(n=61)$

\begin{tabular}{llll}
\hline & First visit & Last visit & P \\
\hline Sex & $2010 \pm 5$ & $2014 \pm 3$ & \\
Age (years) & Female $88 \%$ & & $<0.05$ \\
T3 (ng/dL) & $53 \pm 14$ & $104 \pm 26$ & $10.9 \pm 11.4$ \\
T4 ( $\mu$ g/dL) & $129 \pm 40$ & $1.4 \pm 0.4$ & $<.5 \pm 4.8$ \\
FT4 (ng/dL) & $9.1 \pm 3.2$ & $150 \pm 874$ & $<0.05$ \\
TSH $(\mu \mathrm{U} / \mathrm{mL})$ & $1.2 \pm 0.3$ & $22 \pm 35$ & $<0.05$ \\
TPOAb $(\mathrm{U} / \mathrm{mL})$ & $1.5 \pm 1.3$ & $27 \pm 95$ & $<0.05$ \\
TgAb $(\mathrm{U} / \mathrm{mL})$ & $190 \pm 734$ & $19 \pm 96$ & $<0.05$ \\
Tg $(\mathrm{ng} / \mathrm{mL})$ & $43 \pm 66$ & $11.4 \pm 3.4$ & \\
Calcitonin $(\mathrm{pg} / \mathrm{mL})$ & $882 \pm 2,249$ & \\
T3/T4 (no dimensional) & $558 \pm 3,332$ & & \\
Enlarged thyroid $(\%)$ & $14.7 \pm 4.9$ & & \\
Nodules $(\%)$ & $53 \%$ & & \\
Cytology & $87 \%$ & Neoplasia $66 \%$ & \\
\hline
\end{tabular}

T3: triiodothyronine; T4: thyroxine; TSH: thyroid stimulating hormone; fT4: free thyroxine; TPOAb: thyroid peroxidase antibody; TgAb: thyroglobulin antibody; Tg: thyroglobulin.

felt by the experienced physician, occur in $5 \%$ of the general population while sonographically defined thyroid nodules of $2-3 \mathrm{~mm}$ in size occur in more than $30 \%$. TN occurs in more than $30 \%$ of the general population if pathologic data is con-

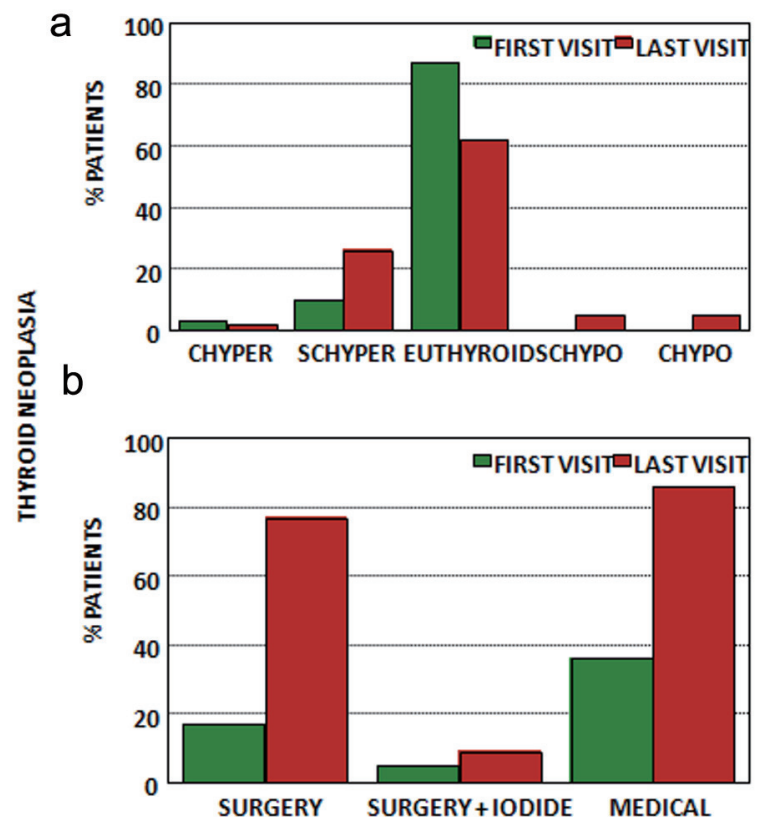

Figure 6. (a) Thyroid function at first and last visits for patients with thyroid neoplasia. (b) Treatment at first and last visits for patients with thyroid neoplasia. CHyper: clinical hyperthyroidism; SCHyper: subclinical hyperthyroidism; euthyroid: euthyroidism; SCHypo: subclinical hypothyroidism; CHypo: clinical hypothyroidism; iodide: radioactive iodide medical treatment: anti-thyroid drugs and/or levothyroxine (see text). sidered, even if it remains an uncommon neoplasia at the clinical level and furthermore with minor mortality [5-9].

Thyroid diseases and disorders account for most of the activity of outpatient endocrine departments. However objective data regarding the care of such patients in the real setting of hospital care and outside the research setting, namely regarding follow-up and outcomes, is not easy to find [1-2].

This report presents data in the real conditions of clinical practice in a public central university hospital in Portugal. It includes five major groups of thyroid diseases and disordersGD, HT, TNG, SNG and TN-each with an adequate number of patients, and with a convenient follow-up of 5 years, along a natural history as modified by medical intervention of 10 years. Portugal is a rather small homogeneous country with $10,000,000$ inhabitants and around 200 practicing endocrinologists and this may help contextualize the data [16]; in particular from the estimated prevalence and the population size absolute numbers regarding the different conditions in Portugal may be computed, and from the present data and the number of practicing endocrinologists, patient load may be estimated.

Not unexpectedly thyroid diseases and disorders are the largest group of conditions assisted at the outpatient clinic at $39 \%$ of the total. Furthermore SNG (46\%) and HT (28\%) account for the majority of the patients, and these are generally considered benign clinically irrelevant conditions $[5,6]$.

Most patients are middle-aged women, but interestingly enough, more male patients can be found in GD and TN occurs in younger women. Two-thirds of the patients were new cases and two-thirds of the patients persist in the follow-up. Continued care is the rule even if administrative discharge for the general physician is strongly encouraged.

At the first appointment patients with GD, HT and TN are already being treated, even if thyroid dysfunction is the rule for 
patients with GD, TNG or even HT. After a mean follow-up of 5 years not significantly different across diagnostic groups, and with one - two visits per year in GD or HT or just one visit per year regarding patients with SNG, the euthyroid state is common but far from universal and most patients either received definitive treatment or were being treated, even one-third of those with SNG.

A closer look at the individual entities considered further clarifies specific characteristics of thyroid care.

\section{GD}

GD accounts for between $60-90 \%$ of all cases of thyrotoxicosis and even a larger fraction of patients with hyperthyroidism $[7,17,18]$. At an estimated prevalence of $2-3 \%$ for hyperthyroidism, and given the above data regarding this country-there would be 250,000 GD in Portugal and 25,000 assisted by endocrinologists-it would seem that at any moment, 1/10 of the patients are being assisted by the specialists and the remainder by their general physicians [17, 18].

Patients with GD, also in this report are generally female and middle-aged; the thyroid is enlarged in slightly more than half of the patients and thyroid nodules were present in almost half; evidence for thyroid autoimmunity was exuberant including positive TRAb; the T3/T4 ratio is increased $(25: 1)$ and Tg levels are mildly increased. Some had the disease for some time and many were already under treatment at the first appointment but most were hyperthyroid and few were euthyroid $[7,13,14,17-20]$. This suggests limitations regarding nonspecialist care.

After a mean follow-up of 5 years the condition was corrected in most patients: a euthyroid state is attained, and the T3/T4 ratio and Tg levels were greatly lowered. However the problem is not solved. After a mean of 9 years since diagnosis, definitive treatment was prescribed in only one-third of the patients and the euthyroid state was achieved in only two-thirds of the patients, with two-thirds of the patients under medical treatment. This suggests a rather conservative approach by the specialists, bearing in mind the primum non nocere principle [17-25].

It is doubtful if treatment has any direct effect on the basic pathogenic process [26]. There is still controversy regarding the "best" treatment, with medical treatment for one - two years being the favored initial option, with "definitive" treatments being reserved for recidives, generally radioactive iodine, while surgery generally near total thyroidectomy reserved for special cases, like children, pregnant women or subjects with large goiters, with a $1 \%$ risk of laryngeal nerve damage and $1 \%$ of hypoparathyroidism [17, 18, 27].

Long-term follow-up of these patients is probably the responsibility of the endocrine team, since hyperthyroidism and hypothyroidism are deemed to occur even if one-third of the patients remain apparently free of the disease. In fact recidives should be expected in about $50 \%$ of the patients after medical treatment and even more in the long term (70-80\%), and relapses can occur at any time, although more common in the beginning $[17,18,28]$. Furthermore "definitive" treatment almost always results in hypothyroidism in surgically treated patients and it occurs in up to $90 \%$ of the patients in the first year after radioactive iodine depending on the dose used [18-25].

\section{TNG}

These results may be contrasted to those regarding patients with TNG. At two-thirds of the total number of patients with GD, this would suggest a higher than expected prevalence of the disease and therefore may suggest iodine deficiency in Portugal $[7,8]$. In fact, literature suggests TNG to be responsible for only $10-20 \%$ of cases of hyperthyroidism [29-32]. Given the numbers as before this would suggest that around one-third of the patients were being treated at any moment by the specialists, a higher ratio than that found for GD.

Patients are also mostly female, and significantly older as expected; the thyroid was enlarged in most patients and thyroid nodules were always found; hyperthyroidism was slightly less severe, with an increased T3/T4 ratio lower than in GD with higher Tg levels. Less patients than those with GD were already being treated at the first appointment perhaps in relation with less severe hyperthyroidism, but it should be noted that $11 \%$ had already been treated with what was supposed to be a definitive treatment-either thyroidectomy or radioactive iodine [8, 13, 14, 29-32].

At the end of the follow-up period of only 4 years, less than in GD and with less appointments, the condition was corrected in most patients with an euthyroid state and decreased Tg levels. However no definitive treatment was used in $24 \%$ of the patients meaning that hyperthyroidism may again recur. A total of $60 \%$ had "definitive" treatment again using a conservative approach since most of them did not require replacement therapy after radioactive iodine [8, 26, 29-32].

It is now known that the condition generally depends on activating mutations of the TSH receptor either in the oncogenic process in single adenomas, or by chance event in hyperplastic multinodular goiter in relation to iodine deficiency $[8,33]$. Spontaneous remissions should not be expected. Interestingly enough it has been suggested that SNG evolves to toxic multinodular goiter at a rate of $9-10 \%$ per year. We suppose that the no spontaneous remission applies to the "adenoma" subgroup while transient hyperthyroidism may be common in hyperplastic SNG with iodide surcharge [8, 29-32].

Radioiodine is a highly selective therapy-success rate of $80-90 \%$ with euthyroid state in 1 - 3 months with a low risk of a transient exacerbation of hyperthyroidism because of radiation thyroiditis-since furthermore only hyperplasic autonomous tissue will uptake the isotope with the generally used 10 - $20 \mathrm{mCi}$ dose (we used 5-10 mCi); however such selectivity may be questioned at least at the doses recommended since hypothyroidism is common in the long course- $7 \%$ in the first year, $28 \%$ at 5 years, $46 \%$ at 10 years and $60 \%$ at 20 years. Surgery after the euthyroid state is obtained is another effective option [8, 29-32, 34, 35].

Because of recurrence risk and long-term hypothyroidism these conditions must also be cared for continually by the specialists at tertiary centers. Hyperthyroidism may be particu- 
larly relevant in old people, like this group, because it may be asymptomatic-and most of these patients were indeed not treated when first seen-and may be associated with atrial fibrillation, increased cardiovascular mortality and reduced bone mineral density and fragility fractures [36-38].

\section{HT}

Patients with HT represent the other spectrum of thyroid diseases with thyroid dysfunction [6]. Much more common than either GD or TNG, this is by far the most common reason for hypothyroidism in the adult population and in areas without gross iodine deficiency, and all other reasons are much less common [39-41]. It should be noted however that HT must be defined at the clinical level by positive thyroid auto-antibodies, since FNAC is not justified in most cases; in fact baseline levels of TSH not antibody levels are predictive of hypothyroidism development-yearly $1 \%$ risk for those with TSH $>2.5 \mathrm{U} / \mathrm{L}$ and $0.2 \%$ for those with TSH $<2.5 \mathrm{U} / \mathrm{L}[6,39-41]$.

Using the same numbers as before and since the prevalence of hypothyroidism is similar to that of hyperthyroidism it would seem that a larger rate at about $15 \%$ are assisted by the specialists at any moment while the remainder are followed by their GP.

Globally patients are mainly female with a ratio of $9: 1$ even higher than in GD, are slightly older than those with GD, the T3/T4 ratio is only slightly non-significantly increased (15:1), thyroid autoimmunity is present but less dramatically so than in GD, Tg is also only slightly increased (it is not increased in most patients as noted given the large standard deviation), the thyroid is not enlarged (in fact it is enlarged in $1 / 3$ and decreased in 1/10) and most present sonographically defined thyroid nodules [19, 20, 39-41].

At the end of the follow-up period, the T3/4 ratio abates (13:1) as does $\mathrm{Tg}$, but thyroid autoimmunity remains almost unchanged. Both non-increased thyroid and clearly defined nodules suggest long standing disease since it is generally accepted that a goitrous form may precede an atrophic later form. In fact patients having that diagnosis 5 years ago were followed for 5 years, with one - two appointments per year, and now have the disease for 10 years [39-41].

When referred for specialist care almost half are already under levothyroxine treatment meaning it is hypothyroidism, not just positive antibody titers as the reason for referral and after 5 years of follow-up 2/3 were under that therapy. In fact these patients should be followed by the specialists since they are rapidly developing hypothyroidism with $19 \%$ in 5 years requiring therapy, almost $4 \%$ per year, much more rapidly than the $0.5-1 \%$ per year reported in the literature [39-41].

Treatment is advocated only when hypothyroidism develops and therefore no modulation of the disease process is attempted, although levothyroxine treatment may reduce goiter size and decrease thyroid antibody levels [39-41].

That although treatment is deemed easy it seems rather far from perfect is evident since even with specialist care almost a quarter presented thyroid dysfunction, either subclinical or clinical hypothyroidism or hyperthyroidism and these rates are not very different regarding the first appointment. Treatment of hypothyroidism is far from perfect even if it is easy, since many factors affect the daily dose needed, many drug interactions are recognized and non-adherence even self-reported is great, even if we do not consider ongoing controversies regarding the advantages of also replacing T3 [42]. One study showed that regarding patients being treated with levothyroxine, $18 \%$ had increased TSH levels and $22 \%$ decreased TSH levels, with rates not very different from those found in the present report [43].

Again this suggests that these patients should be preferably followed up by the specialists, either because of the high rate of developing hypothyroidism or because of difficulty in reaching and maintaining the euthyroid state. As noted hypothyroidism may have systemic undesirable effects and administrative discharge for the GP hides but not solves the problem [44-46].

\section{SNG}

Data regarding patients with SNG are somehow perplexing. As noted, they are by far the largest group.

Amazingly diagnosis is recent contrasting with the other groups, suggesting that patients are referred very soon once a thyroid nodule is found. Using the same methods as before, 100,000 patients, so one-fifth of all palpable thyroid nodules are at any moment followed up by the specialist [47].

Patients are again women, middle-aged, with normal thyroid function and no evidence for thyroid autoimmunity. Only half presented with enlarged thyroid and multinodular goiter is much more common than a single dominant nodule (4:1). Also it should be noted that at the first appointment even if euthyroid the ratio T3/T4 is increased (15:1) and so is Tg, and that at the end of the follow-up both significantly decreased to 12:1 and to two-thirds of the initial values, respectively. FNAB was obtained in almost half suggesting only half presented thyroid nodules greater than $10 \mathrm{~mm}$ or with suspicious features [19, 20, 48-50].

Considering data from the first appointment, although patients were by far euthyroid, a sizable fraction had already undergone surgery $(7 \%)$ and another sizable fraction were prescribed levothyroxine $(12 \%)$. Because of this, one-sixth presented thyroid dysfunction- $6 \%$ hyperthyroid and $8 \%$ hypothyroid.

At the end of the rather short follow-up period one-third were being treated, and $22 \%$ received thyroid surgery, $15 \%$ more than at the beginning more or less $4 \%$ per year and the same $12 \%$ were under levothyroxine treatment.

Age and iodine deficiency are the major pathogenic factors identified, even if an increasing list of organic and inorganic goitrogens go on being described [51,52]. Compressive symptomatology, acute pain from nodule hemorrhage, hyperthyroidism $(9-22 \%)$ and the risk of neoplasia $(5-10 \%)$ are the major concerns regarding patients with SNG [48-50]. Compressive symptomology seems real since in less than 5 years of follow-up $15 \%$ of the patients received thyroid surgery; hyperthyroidism is also real since 83 patients in this report oneseventh of those with SNG presented with TNG and the same can be said regarding TN. Predictive factors for hyperthyroid- 
ism or neoplasia, are doubtful if any, besides the usual clinical workup [48-50, 53-56].

Therefore this would seem to indicate that these patients should also be followed up by the specialists given the small albeit non-negligible risk of compressive symptomatology, hyperthyroidism, neoplasia and iatrogenic thyroid dysfunction. There is no consensus for the management of thyroid nodules, although expectant management is a reasonable approach since growth is slow with no change in 5 years, risk of hyperthyroidism is also small as is the risk of neoplasia [5, $48-50,57,58]$. Sonography every $1-2$ years and FNAB if nodule characteristic change are the mainstay of that expectant management [48-50, 59-61]. Levothyroxine therapy is not recommended since in the long term it is not effective regarding reduction of thyroid or nodules size. Compressive symptomatology may require thyroidectomy, although in older poor risk surgical patients radioactive iodine may be an option since thyroid dimensions reduce by $30-40 \%$ in the first year and by $50-60 \%$ at 3 years $[48-50]$.

\section{TN}

Finally there are data regarding patients with $\mathrm{TN}$; the implicit threat when evaluating thyroid nodular disease is not unexpected.

Sixty-one patients were found accounting for $5 \%$ of all patients and $11 \%$ of the patients with SNG suggesting a risk of $10 \%$ for $\mathrm{TN}$ in patients with SNG [62-64]. Considering the same numbers as before 12,000 patients with TN would be followed up by the specialists at any moment. If we consider only the very aggressive undifferentiated neoplasia, 400 patients would be followed up and this is what should be expected since the mortality is very high in this group, and the mortality because of TN is about $60-100$ patients per year in Portugal [65].

Patients are mainly female, middle-aged adults. Thyroid function is normal with minimal evidence of thyroid autoimmunity, but serum markers of TN-Tg and calcitonin are greatly increased $[20,66]$. Thyroid nodules were almost always present but the thyroid was only enlarged in half. The diagnosis arises because of the workup of thyroid nodules, again suggesting a $10 \%$ risk. In fact diagnosis is established by cytology and/or histology and in 10-20\% only by histology with negative cytology, while $10 \%$ of those with suspicious cytology are not confirmed by histology [67-70]. The histologic distribution is not different from what should be expected-papillary carcinoma, follicular carcinoma, undifferentiated carcinoma and medullary carcinoma, even if the rate of the last two is higher than would probably be expected [67-71].

At the first visit a quarter were already being treated. Many patients already known that they have the disease when first seen, the follow-up is short, and the number of appointments is small. At the last appointment patients have the disease for 7 years and have been followed up for 4 years. At the end of the follow-up $86 \%$ had been treated and only $64 \%$ are still followed up at this institution while the remainder were lost for the follow-up although many were referred to other institutions at the National Health System, since treatment of TN is centralized at the National Cancer Institute. For this reason no mortality was recorded in this institution [72-74].

Thyroid nodules are very common in the general population either clinically or by sonography [47]. Clinical and sonographic data suggest suspicious nodules that require fine needle thyroid cytopathology, the gold standard for the evaluation of thyroid nodules and now generally reported using the Bethesda scoring system [59-61, 67-70]. Staging is very easy since only neck sonography is required, other methods being performed after surgery [75-77]. Treatment is also straightforward and the prognosis is very good [67-74].

TN accounts for only $1-5 \%$ of all neoplasia in men and women and because their good prognosis accounts for an even less rate of neoplasia deaths between $0.2-0.3 \%[63,67]$; however the incidence is rapidly increasing although this increase is mainly due to increased detection of early papillary carcinoma with a very good prognosis anyway [63, 78-81]; they arise earlier than most carcinomas (49 vs. 66 years) and is three times more common in women. Papillary carcinomas (70\%) and follicular carcinomas (10-40\%) account for the majority, while anaplastic and medullary carcinomas account for only $5 \%$ [67-71].

The most clear pathogenic factor is radiation exposure in general and iodine deficiency with SNG for follicular carcinomas [51, 52, 67-70]; radiation exposure may however occur at a very early age, many years before TN is clinically recognized but the relation is linear with the dose beginning with very low doses of 0.05 Gy and the effect is more evident for radiation exposure in childhood [62, 67-70]. TSH is also a recognized risk factor since a direct relation is found even for normal TSH levels [54, 62, 67-70]. The theoretical evolution accepted is SNG-follicular adenoma-well differentiated follicular carcinoma-poorly differentiated follicular carcinoma [62, 67-70]. Some genetic syndromes like Gardner syndrome, Cowden syndrome, Werner syndrome and adenomatous polyposis intestinal syndrome have an increased risk for thyroid carcinoma and these familiar forms may present a more aggressive behavior [62, 67-70, 82].

By definition these are monoclonal processes, and the oncogenic process according to the Knudson model emphasizes the role of proto-oncogenes and tumor-suppressing genes namely along the $P I 3 K$ and $M A P K$ pathways. Main genes implicated include the RET (1-20\%) and $B R A F(45-50 \%)$ for papillary carcinomas, $P A X 8 / P P A R \gamma(35 \%)$ and $R A S(40-50 \%)$ for follicular carcinomas and $P I 3 K$ and TP53 for the undifferentiated carcinoma $[62,67-70,82]$. However genetic data although potentially useful both for the diagnosis and treatment has not yet reached widespread clinical application [56, 67-70].

Management includes total thyroidectomy as well as postoperative staging with the TNM model including age as a relevant prognostic factor [67-70, 72-74]. Radioactive iodine is reserved for those extending behind the thyroid or presenting vascular invasion and/or for high risk patients [67-70, 72-74]. Follow-up is by $\mathrm{Tg}$ and $\mathrm{TgAb}$ levels and therapeutic and diagnostic radioactive iodide $(100-200 \mathrm{mCi})$, or sometimes positron emission tomography (PET) scan [67-70, 72-74, 83]. Undifferentiated or non-iodine uptaking lesions may benefit even if transiently for taxans or platin derivatives and/or tyrosine 
kinase inhibitors [66, 84-87].

In short, objective evaluation of outpatient diagnosis and treatment of thyroid diseases and disorders confirm common assumptions but emphasize some neglected aspects: 1) The diagnosis and treatment of thyroid diseases and disorders may be carried out at the outpatient department since it rarely requires dynamic tests, in patient care or emergency care; the last two are however a hidden component of thyroid care since it escapes specialist endocrine care and is assured by internal medicine specialists $[88,89]$; 2) The clinical diagnosis and treatment of thyroid diseases and disorders requires support from a endocrine lab, general sonographic imaging, specialist pathologic examination of FNAB and surgical samples, nuclear medicine facilities and a molecular and genetic research lab if up to date care is aimed; 3 ) The diagnosis and treatment of thyroid diseases and disorders are easy, inexpensive and nonsophisticated; it is also very effective although common caveats should be borne in mind; 4) No cure is available for most thyroid diseases and disorders and treatment is only corrective of abnormal thyroid function; 5) Continuing treatment is necessary since these are chronic conditions not cured but treated; and 6) Continued care is best assured by the endocrine specialist at tertiary centers, since the euthyroid state is difficult to attain and even more to maintain, recidives are common, and long-term complications present no negligible consequences [90]; so far this remains a hidden problem and only later major complications come to the attention of the endocrine specialists $[9,89]$.

In summary diagnosis and treatment of thyroid diseases and disorders are not more effective than the care of diabetic patients, although this is much more complex, time consuming, expensive and sophisticated and drawbacks of less than optimal care are more easily recognized, namely acute metabolic decompensations and long-term micro- and macrovascular diseases.

\section{Acknowledgments}

None.

\section{Financial Disclosure}

There is no funding. This report derives from the clinical activity of the authors in a public central hospital.

\section{Conflict of Interest}

Authors state that there is no conflict of interest regarding this work.

\section{Informed Consent}

All patients signed a written informed consent regarding the use of clinical data for research purposes at the public central and academic hospital.

\section{Author Contributions}

JMM assisted the patients, retrieved the data, performed the statistical analysis and wrote the manuscript; DR discussed the patients and thoroughly discussed and corrected the manuscript; LB performed the surgery and thoroughly discussed and corrected the manuscript; FP supervised the analytical methods and thoroughly discussed and corrected the manuscript; MMA performed the pathologic analysis and thoroughly discussed and corrected the manuscript; and GC performed the nuclear imaging methods and thoroughly discussed and corrected the manuscript.

\section{References}

1. Brennan MD, Miner KM, Rizza RA. Profiles of the endocrine clinic: the Mayo clinic. J Clin Endocrinol Metab. 1998;83(10):3427-3434.

2. Hing E, Cherry DK, Woodwell DA. National ambulatory medical care survey: 2004 summary. Adv Data. 2006;374:1-33.

3. Martins JM, do Vale S, Martins AF, Gomes AR, Vicente L, Caldeira J. Outpatient diabetic care in a public central hospital: patient characteristics, therapeutic regimens and results. J Endocrinol Metab. 2014;4(1-2):13-24.

4. Cibas ES, Ali SZ, NCI Thyroid FNA State of the Science Conference. The Bethesda System For Reporting Thyroid Cytopathology. Am J Clin Pathol. 2009;132(5):658-665.

5. Haugen BR, Alexander EK, Bible KC, Doherty GM, Mandel SJ, Nikiforov YE, Pacini F, et al. 2015 American Thyroid Association Management Guidelines for adult patients with thyroid nodules and differentiated thyroid cancer: the American Thyroid Association Guidelines Task Force on thyroid nodules and differentiated thyroid cancer. Thyroid. 2016;26(1):1-133.

6. Caturegli P, De Remigis A, Rose NR. Hashimoto thyroiditis: clinical and diagnostic criteria. Autoimmun Rev. 2014;13(4-5):391-397.

7. Marino M, Vitti P, Chiovato L. Graves' disease. In: Jameson JL, De Groot LJ, senior eds. Endocrinology. Adult and Pediatric. Volume II. 7th ed. Philadelphia: Elsevier Saunders, 2016:1437-1464.

8. Paschle R. Toxic adenoma and toxic multinodular goiter. In: Braverman LE, Cooper DS, eds. Werner \& Ingbar's The Thyroid. A fundamental and clinical text. 10th ed. Philadelphia: Lippincott, Williams \& Wilkins, Wolters Kluwer, 2013:400-409.

9. Cobin RH, Gharib H, Bergman DA, Clark OH, Cooper DS, Daniels GH, Dickey RA, et al. AACE/AAES medi$\mathrm{cal} /$ surgical guidelines for clinical practice: management of thyroid carcinoma. American Association of Clinical Endocrinologists. American College of Endocrinology. Endocr Pract. 2001;7(3):202-220.

10. Wonnacott TH, Wonnacott RJ. Introductory statistics. 5th ed. New York: John Wiley \& Sons, 1990. 
11. Norman GR, Streiner DL. Biostatistics. The bare essentials. St. Louis: Mosby Year Book Inc., 1994.

12. Cohen BH. Explaining psychological statistics. 2nd ed. New York: John Wiley \& Sons, Inc., 2001.

13. Vanderpump MP, Tunbridge WM, French JM, Appleton D, Bates D, Clark F, Grimley Evans J, et al. The incidence of thyroid disorders in the community: a twenty-year follow-up of the Whickham Survey. Clin Endocrinol (Oxf). 1995;43(1):55-68.

14. Golden SH, Robinson KA, Saldanha I, Anton B, Ladenson PW. Clinical review: Prevalence and incidence of endocrine and metabolic disorders in the United States: a comprehensive review. J Clin Endocrinol Metab. 2009;94(6):1853-1878.

15. Surks MI, Hollowell JG. Age-specific distribution of serum thyrotropin and antithyroid antibodies in the US population: implications for the prevalence of subclinical hypothyroidism. J Clin Endocrinol Metab. 2007;92(12):4575-4582.

16. Instituto Nacional de Estatistica. Estatisticas da Saude 2015. Lisboa: Instituto Nacional de Estatistica, 2017.

17. De Leo S, Lee SY, Braverman LE. Hyperthyroidism. Lancet. 2016;388(10047):906-918.

18. Smith TJ, Hegedus L. Graves' Disease. N Engl J Med. 2016;375(16):1552-1565.

19. Carle A, Knudsen N, Pedersen IB, Perrild H, Ovesen L, Rasmussen LB, Laurberg P. Determinants of serum T4 and $\mathrm{T} 3$ at the time of diagnosis in nosological types of thyrotoxicosis: a population-based study. Eur J Endocrinol. 2013;169(5):537-545.

20. Di Jeso B, Arvan P. Thyroglobulin from molecular and cellular biology to clinical endocrinology. Endocr Rev. 2016;37(1):2-36

21. Cooper DS. Antithyroid drugs. N Engl J Med. 2005;352(9):905-917.

22. Allannic H, Fauchet R, Orgiazzi J, Madec AM, Genetet B, Lorcy Y, Le Guerrier AM, et al. Antithyroid drugs and Graves' disease: a prospective randomized evaluation of the efficacy of treatment duration. J Clin Endocrinol Metab. 1990;70(3):675-679.

23. Ma C, Xie J, Wang H, Li J, Chen S. Radioiodine therapy versus antithyroid medications for Graves' disease. Cochrane Database Syst Rev. 2016;2:article CD010094.

24. Sundaresh V, Brito JP, Wang Z, Prokop LJ, Stan MN, Mu$\operatorname{rad} \mathrm{MH}, \mathrm{Bahn} \mathrm{RS}$. Comparative effectiveness of therapies for Graves' hyperthyroidism: a systematic review and network meta-analysis. J Clin Endocrinol Metab. 2013;98(9):3671-3677.

25. Vos XG, Endert E, Zwinderman AH, Tijssen JG, Wiersinga WM. Predicting the Risk of Recurrence Before the Start of Antithyroid Drug Therapy in Patients With Graves' Hyperthyroidism. J Clin Endocrinol Metab. 2016;101(4):1381-1389.

26. Struja T, Guebelin L, Kutz A, Fehlberg H, Mueller B, Schuetz P. Does immunosuppressive therapy improve outcomes in Graves' disease? A Systematic Review and Meta-Analysis. Thyroid. 2016;26(5):634-640.

27. Ross DS, Burch HB, Cooper DS, Greenlee MC, Laurberg P, Maia AL, Rivkees SA, et al. 2016 American Thyroid
Association Guidelines for diagnosis and management of hyperthyroidism and other causes of thyrotoxicosis. Thyroid. 2016;26(10):1343-1421.

28. Mohlin E, Filipsson Nystrom H, Eliasson M. Long-term prognosis after medical treatment of Graves' disease in a northern Swedish population 2000-2010. Eur J Endocrinol. 2014;170(3):419-427.

29. Siegel RD, Lee SL. Toxic nodular goiter. Toxic adenoma and toxic multinodular goiter. Endocrinol Metab Clin North Am. 1998;27(1):151-168.

30. Vitti P, Rago T, Tonacchera M, Pinchera A. Toxic multinodular goiter in the elderly. J Endocrinol Invest. 2002;25(10 Suppl):16-18.

31. Carle A, Andersen SL, Boelaert K, Laurberg P. MANAGEMENT OF ENDOCRINE DISEASE: Subclinical thyrotoxicosis: prevalence, causes and choice of therapy. Eur J Endocrinol. 2017;176(6):R325-R337.

32. Vadiveloo T, Donnan PT, Cochrane L, Leese GP. The Thyroid Epidemiology, Audit, and Research Study (TEARS): the natural history of endogenous subclinical hyperthyroidism. J Clin Endocrinol Metab. 2011;96(1):E1-8.

33. Paschke R, Ludgate $M$. The thyrotropin receptor in thyroid diseases. N Engl J Med. 1997;337(23):1675-1681.

34. Ceccarelli C, Bencivelli W, Vitti P, Grasso L, Pinchera A. Outcome of radioiodine-131 therapy in hyperfunctioning thyroid nodules: a 20 years' retrospective study. Clin Endocrinol (Oxf). 2005;62(3):331-335.

35. Yano Y, Sugino K, Akaishi J, Uruno T, Okuwa K, Shibuya $\mathrm{H}$, Kitagawa W, et al. Treatment of autonomously functioning thyroid nodules at a single institution: radioiodine therapy, surgery, and ethanol injection therapy. Ann Nucl Med. 2011;25(10):749-754.

36. Parle JV, Maisonneuve P, Sheppard MC, Boyle P, Franklyn JA. Prediction of all-cause and cardiovascular mortality in elderly people from one low serum thyrotropin result: a 10-year cohort study. Lancet. 2001;358(9285):861-865.

37. Vadiveloo T, Donnan PT, Cochrane L, Leese GP. The Thyroid Epidemiology, Audit, and Research Study (TEARS): morbidity in patients with endogenous subclinical hyperthyroidism. J Clin Endocrinol Metab. 2011;96(5):13441351.

38. Blum MR, Bauer DC, Collet TH, Fink HA, Cappola AR, da Costa BR, Wirth CD, et al. Subclinical thyroid dysfunction and fracture risk: a meta-analysis. JAMA. 2015;313(20):2055-2065.

39. Weetman AP. Chronic autoimmune thyroiditis. In: Braverman LE, Cooper DS, eds. Werner \& Ingbar's The Thyroid. A fundamental and clinical text. 10th ed. Philadelphia: Lippincott, Williams \& Wilkins, Wolters Kluwer, 2013:525-535.

40. Brent GA, Weetman AP. Hypothyroidism and thyroiditis. In: Melmed S, Polonsky KS, Larsen PR, Kronenberg HM, eds. Williams textbook of endocrinology. 13th ed. Philadelphia: Elsevier, 2016:416-448.

41. Almandoz JP, Gharib H. Hypothyroidism: etiology, diagnosis, and management. Med Clin North Am. 2012;96(2):203-221.

42. Carter Y, Sippel RS, Chen H. Hypothyroidism after a cancer diagnosis: etiology, diagnosis, complications, and 
management. Oncologist. 2014;19(1):34-43.

43. Canaris GJ, Manowitz NR, Mayor G, Ridgway EC. The Colorado thyroid disease prevalence study. Arch Intern Med. 2000;160(4):526-534.

44. Thvilum M, Brandt F, Brix TH, Hegedus L. A review of the evidence for and against increased mortality in hypothyroidism. Nat Rev Endocrinol. 2012;8(7):417-424.

45. Cooper DS, Biondi B. Subclinical thyroid disease. Lancet. 2012;379(9821):1142-1154.

46. Biondi B. Natural history, diagnosis and management of subclinical thyroid dysfunction. Best Pract Res Clin Endocrinol Metab. 2012;26(4):431-446.

47. Dean DS, Gharib H. Epidemiology of thyroid nodules. Best Pract Res Clin Endocrinol Metab. 2008;22(6):901911.

48. Graf H. Multinodular goiter: pathogenesis and management. In: Braverman LE, Cooper DS, eds. Werner \& Ingbar's The Thyroid. A fundamental and clinical text. 10th ed. Philadelphia: Lippincott, Williams \& Wilkins, Wolters Kluwer, 2013:635-649.

49. Mandel SJ, Langer JE, Kaplan MM. Clinical evaluation and management of thyroid nodules. In: Braverman LE, Cooper DS, eds. Werner \& Ingbar's The Thyroid. A fundamental and clinical text. 10th ed. Philadelphia: Lippincott, Williams \& Wilkins, Wolters Kluwer, 2013:649-664.

50. Burman KD, Wartofsky L. Clinical practice. Thyroid Nodules. N Engl J Med. 2015;373(24):2347-2356.

51. Zimmermann MB, Boelaert K. Iodine deficiency and thyroid disorders. Lancet Diabetes Endocrinol. 2015;3(4):286-295.

52. Katagiri R, Yuan X, Kobayashi S, Sasaki S. Effect of excess iodine intake on thyroid diseases in different populations: A systematic review and meta-analyses including observational studies. PLoS One. 2017;12(3):e0173722.

53. Durante C, Costante G, Lucisano G, Bruno R, Meringolo D, Paciaroni A, Puxeddu E, et al. The natural history of benign thyroid nodules. JAMA. 2015;313(9):926-935.

54. Boelaert K, Horacek J, Holder RL, Watkinson JC, Sheppard MC, Franklyn JA. Serum thyrotropin concentration as a novel predictor of malignancy in thyroid nodules investigated by fine-needle aspiration. J Clin Endocrinol Metab. 2006;91(11):4295-4301.

55. Grani G, Fumarola A. Thyroglobulin in lymph node fineneedle aspiration washout: a systematic review and metaanalysis of diagnostic accuracy. J Clin Endocrinol Metab. 2014;99(6):1970-1982.

56. Cantara S, Capezzone M, Marchisotta S, Capuano S, Busonero G, Toti P, Di Santo A, et al. Impact of protooncogene mutation detection in cytological specimens from thyroid nodules improves the diagnostic accuracy of cytology. J Clin Endocrinol Metab. 2010;95(3):13651369.

57. Paschke R, Hegedus L, Alexander E, Valcavi R, Papini $\mathrm{E}$, Gharib H. Thyroid nodule guidelines: agreement, disagreement and need for future research. Nat Rev Endocrinol. 2011;7(6):354-361.

58. Burch HB, Burman KD, Cooper DS, Hennessey JV, Vietor NO. A 2015 survey of clinical practice patterns in the management of thyroid nodules. J Clin Endocrinol Me- tab. 2016;101(7):2853-2862.

59. Remonti LR, Kramer CK, Leitao CB, Pinto LC, Gross JL. Thyroid ultrasound features and risk of carcinoma: a systematic review and meta-analysis of observational studies. Thyroid. 2015;25(5):538-550.

60. Frates MC, Benson CB, Doubilet PM, Kunreuther E, Contreras M, Cibas ES, Orcutt J, et al. Prevalence and distribution of carcinoma in patients with solitary and multiple thyroid nodules on sonography. J Clin Endocrinol Metab. 2006;91(9):3411-3417.

61. Singh Ospina N, Brito JP, Maraka S, Espinosa de Ycaza AE, Rodriguez-Gutierrez R, Gionfriddo MR, CastanedaGuarderas A, et al. Diagnostic accuracy of ultrasoundguided fine needle aspiration biopsy for thyroid malignancy: systematic review and meta-analysis. Endocrine. 2016;53(3):651-661.

62. Schneoder AB, Brenner AV. Carcinomas of follicular epithelium: epidemiology and pathogenesis. In: Braverman LE, Cooper DS, eds. Werner \& Ingbar's The Thyroid. A fundamental and clinical text. 10th ed. Philadelphia: Lippincott, Williams \& Wilkins, Wolters Kluwer, 2013:665681.

63. Davies L, Welch HG. Increasing incidence of thyroid cancer in the United States, 1973-2002. JAMA. 2006;295(18):2164-2167.

64. Lin JS, Bowles EJA, Williams SB, Morrison CC. Screening for thyroid cancer: updated evidence report and systematic review for the US preventive services task force. JAMA. 2017;317(18):1888-1903.

65. Davies L, Welch HG. Thyroid cancer survival in the United States: observational data from 1973 to 2005. Arch Otolaryngol Head Neck Surg. 2010;136(5):440-444.

66. Maia AL, Siqueira DR, Kulcsar MA, Tincani AJ, Mazeto GM, Maciel LM. Diagnosis, treatment, and follow-up of medullary thyroid carcinoma: recommendations by the Thyroid Department of the Brazilian Society of Endocrinology and Metabolism. Arq Bras Endocrinol Metabol. 2014;58(7):667-700.

67. Schlumberger M-J, Fileti S, Alexander EK, Hay ID. Nontoxic diffuse goiter, nodular thyroid disorders, and thyroid malignancies. In: Melmed S, Polonsky KS, Larsen PR, Kronenberg HM, eds. Williams textbook of endocrinology. 13th ed. Philadelphia: Elsevier, 2016:449-488.

68. Pacini F, Chiofalo F, De Groot LJ. Thyroid neoplasia. In: Jameson JL, De Groot LJ, senior eds. Endocrinology. Adult and Pediatric. Volume II. 7th ed. Philadelphia: Elsevier Saunders, 2016:1601-1628.

69. Fagin JA, Wells SA, Jr. Biologic and clinical perspectives on thyroid cancer. N Engl J Med. 2016;375(11):10541067.

70. Cabanillas ME, McFadden DG, Durante C. Thyroid cancer. Lancet. 2016;388(10061):2783-2795.

71. Hundahl SA, Fleming ID, Fremgen AM, Menck HR. A National Cancer Data Base report on 53,856 cases of thyroid carcinoma treated in the U.S., 1985-1995 [see commetns]. Cancer. 1998;83(12):2638-2648.

72. Randolph GW, Doherty GM. Carcinoma of the follicular epithelium: surgical therapy. In: Braverman LE, Cooper DS, eds. Werner \& Ingbar's The Thyroid. A fundamental 
and clinical text. 10th ed. Philadelphia: Lippincott, Williams \& Wilkins, Wolters Kluwer, 2013:702-711.

73. Mazzaferri EL, Kloos RT. Clinical review 128: Current approaches to primary therapy for papillary and follicular thyroid cancer. J Clin Endocrinol Metab. 2001;86(4):1447-1463.

74. Filetti S, Tuttle RM, Sherman SI. Medical management of differentiated epithelial cell thyroid cancer. In: Braverman LE, Cooper DS, eds. Werner \& Ingbar's The Thyroid. A fundamental and clinical text. 10th ed. Philadelphia: Lippincott, Williams \& Wilkins, Wolters Kluwer, 2013:725-743.

75. Kloss RT. Staging and prognosis of differentiated thyroid cancer. In: Braverman LE, Cooper DS, eds. Werner \& Ingbar's The Thyroid. A fundamental and clinical text. 10th ed. Philadelphia: Lippincott, Williams \& Wilkins, Wolters Kluwer, 2013:712-724.

76. Lang BH, Lo CY, Chan WF, Lam KY, Wan KY. Staging systems for papillary thyroid carcinoma: a review and comparison. Ann Surg. 2007;245(3):366-378.

77. Onitilo AA, Engel JM, Lundgren CI, Hall P, Thalib L, Doi SA. Simplifying the TNM system for clinical use in differentiated thyroid cancer. J Clin Oncol. 2009;27(11):18721878.

78. DeGroot LJ, Kaplan EL, McCormick M, Straus FH. Natural history, treatment, and course of papillary thyroid carcinoma. J Clin Endocrinol Metab. 1990;71(2):414424.

79. Gao X, Zhang X, Zhang Y, Hua W, Maimaiti Y, Gao Z. Is papillary thyroid microcarcinoma an indolent tumor?: A retrospective study on 280 cases treated with radioiodine. Medicine (Baltimore). 2016;95(40):e5067.

80. Lo CY, Chan WF, Lang BH, Lam KY, Wan KY. Papillary microcarcinoma: is there any difference between clinically overt and occult tumors? World J Surg. 2006;30(5):759766.

81. Haigh PI, Urbach DR. The treatment and prognosis of Hurthle cell follicular thyroid carcinoma compared with its
non-Hurthle cell counterpart. Surgery. 2005;138(6):11521157; discussion 1157-1158.

82. Fagin JA, Nikiforov YE. Molecular genetics of tumors of thyroid follicular cells. In: Braverman LE, Cooper DS, eds. Werner \& Ingbar's The Thyroid. A fundamental and clinical text. 10th ed. Philadelphia: Lippincott, Williams \& Wilkins, Wolters Kluwer, 2013:681-702.

83. Giraudet AL, Taieb D. PET imaging for thyroid cancers: Current status and future directions. Ann Endocrinol (Paris). 2017;78(1):38-42.

84. Hu MI, Jimenez C, Cote GJ, Gagel R.F. Medullary thyroid carcinoma. In: Braverman LE, Cooper DS, eds. Werner \& Ingbar's The Thyroid. A fundamental and clinical text. 10th ed. Philadelphia: Lippincott, Williams \& Wilkins, Wolters Kluwer, 2013:744-765.

85. Klopper JP, Kane MA, Haugen BR. Anaplastic thyroid cancer and miscellaneous tumors of the thyroid. In: Braverman LE, Cooper DS, eds. Werner \& Ingbar's The Thyroid. A fundamental and clinical text. 10th ed. Philadelphia: Lippincott, Williams \& Wilkins, Wolters Kluwer, 2013:765-774.

86. Yip L, Sosa JA. Molecular-directed treatment of differentiated thyroid cancer: advances in diagnosis and treatment. JAMA Surg. 2016;151(7):663-670.

87. Viola D, Valerio L, Molinaro E, Agate L, Bottici V, Biagini A, Lorusso L, et al. Treatment of advanced thyroid cancer with targeted therapies: ten years of experience. Endocr Relat Cancer. 2016;23(4):R185-205.

88. Attia J, Margetts P, Guyatt G. Diagnosis of thyroid disease in hospitalized patients: a systematic review. Arch Intern Med. 1999;159(7):658-665.

89. Walsh JP. Managing thyroid disease in general practice. Med J Aust. 2016;205(4):179-184.

90. Ortiz R, Hupart KH, DeFesi CR, Surks MI. Effect of early referral to an endocrinologist on efficiency and cost of evaluation and development of treatment plan in patients with thyroid nodules. J Clin Endocrinol Metab. 1998;83(11):3803-3807. 